\title{
Ventilation Parameters under Adaptive Servo Ventilation: A Comparison on Behalf of CSA-Pattern, BNP/NT-pro-BNP, and Ejection Fraction
}

\author{
Michael Westhoffa, b Patric Litterst ${ }^{a}$ \\ a Department of Pneumology, Sleep and Respiratory Medicine, Hemer Lung Clinic, Hemer, Germany; \\ ${ }^{\text {b} W i t t e n / H e r d e c k e ~ U n i v e r s i t y, ~ W i t t e n, ~ G e r m a n y ~}$
}

\section{Keywords}

Adaptive servoventilation · Central sleep apnoea ·

Cheyne-stokes-respiration - Ventilatory parameters .

Therapeutic pressures · Ejection fraction

\section{Abstract}

Background: The SERVE-HF study has raised questions concerning the higher mortality under adaptive servoventilation. The ventilatory mode was discussed as a possible aggravating factor. Objectives: We wondered if the data recorded by the adaptive servo-ventilation (ASV)-devices in heart failure patients with CSA-CSR \pm OSA are different in terms of respiratory parameters and therapeutic pressures compared to patients with CPAP-resistant/emergent-CSA with normal BNP/NT-pro-BNP. Methods: Patients were included, if ASV had normalized respiratory disturbance index in the first night of application and after at least 6 weeks. ASV-device data were analyzed in terms of respiratory rate $(\mathrm{RR})$, min ventilation (MV), endexpiratory (EEP), peak inspiratory pressure (Ppeak) and median pressure. Results: Compared to CPAP-resistant/emergent-CSA with normal BNP/ NT-pro-BNP $(n=25)$, CSA-CSR- $(n=13)$ CSA-CSR+OSA-patients $(n=32)$ with elevated BNP/NT-pro-BNP had higher RR $(p<0.01)$ in the first night of ASV therapy and during followup (15.3 \pm 1.3 vs. $17.3 \pm 2.4 / \mathrm{min})$ with similar MV (6.5 \pm 1.3 vs. $6.6 \pm 1.3 \mathrm{~L}$ ), resulting in significantly lower tidal volumes. EEP $(5.6 \pm 1.1$ vs. $5.5 \pm 1.1 \mathrm{hPa}$ ), Pmedian and Ppeak ( $9.8 \pm 1.5$ vs. $9.7 \pm 1.2 \mathrm{hPa}$ ) were comparable. Ventilatory parameters were not different between LVEF $<40,40-49$, and $\geq 50 \%$, neither within the whole group nor the group of CSA-CSR \pm OSA and heart failure. Conclusion: Patients with heart failure and CSA-CSR \pm OSA have higher RRs but similar MV under ASVtherapy than patients with CSA and normal BNP. This indicates higher dead space ventilation. EF was not found to have an influence on the ventilatory parameters.

(c) 2018 S. Karger AG, Basel

\section{Introduction}

The pathogenesis of CSA-CSR as well as of CSA is explained by hyperventilation with the $\mathrm{CO}_{2}$-level falling below the apnoea threshold [1-5]. Compared to CSA-CSR, a typical crescendo-decrescendo pattern is missing in idiopathic CSA and CPAP resistant/emergent CSA [6-12]. Hypoventilation is thought to protect against central sleep apnoea; therefore, adaptive servoventilation with (c) 2018 S. Karger AG, Basel

E-Mail karger@karger.com

www.karger.com/res
Michael Westhoff, FCCP

Department of Pneumology, Intensive Care and Sleep Medicine

Hemer Lung Clinic, Theo-Funccius-Strasse 1

DE-58675 Hemer (Germany)

E-Mail michael.westhoff@lkhemer.de 
anti-cyclical pattern of ventilation had been regarded to be an effective treatment in both entities. Adaptive servoventilation (ASV) has so far been applied to patients with CPAP-resistant and emergent CSA as well as in heart failure patients with Cheyne-Stokes respiration (CSA-CSR) [13-19]. A number of studies has shown a normalized breathing pattern and even improved exercise capacity in patients with CSA-CSR $[16,19,20-23]$.

The results of the SERVE-HF study [24] have initiated an extensive discussion, with regard to the increased overall and cardiovascular mortality under ASV therapy of CSA-CSR. Special attention was given to the effects of ASV on the breathing pattern, with a possible aggravation by increased ventilation due to pressure support, which was charged to induce an electrolyte imbalance, thereby increasing the risk for arrhythmias [25-27].

As a consequence of the SERVE-HF study, the positive assessment of the ASV therapy on CSA-CSR and patient outcome has changed.

For understanding the breathing patterns under ASV, it was of interest to analyze the data that have been recorded by the ASV-devices in patients with CPAP resistant/emergent CSA with normal BNP/NT-pro-BNP and patients with CSA-CSR \pm OSA and elevated BNP/ NT-pro-BNP.

\section{Methods}

\section{Study Design}

Patients with ASV therapy for CSA-CSR \pm OSA as well as CPAP-resistant and emergent CSA were included, if the respiratory disturbance index (RDI) was normalized in the first night of ASV therapy and at least 6 weeks after its initiation. Patients who had participated in the SERVE-HF study and had received ASV therapy were included if they fulfilled the aforementioned criteria. Some patients with CPAP resistant/emergent CSA and normal BNP as well as CSA-CSR had participated in former studies [16, 18 ], which however did not focus on ventilatory data. All patients gave their informed consent for evaluating the data.

CPAP titration and adaptation to ASV followed a standardized stepwise protocol for the sleep laboratory $[16,18,28]$, with APAP titration in the first night, CPAP in the second night and when persistence of central apneas initiation of ASV (Auto-CS- ${ }^{\circledR}$ Resmed Inc.), also in patients who had been referred to the sleep lab because of CPAP-resistant CSA. ASV initiation in patients who had participated in the SERVE-HF study followed the criteria given by the study protocol of SERVE-HF [24].

After the first night (baseline) and at least 6 weeks of ASV therapy, the device data were analyzed in terms of median respiratory rate (RR), minute ventilation (MV), and therapeutic pressures (endexpiratory pressure [EEP], peak inspiratory pressure [Ppeak], median pressure [Pmean]). The follow-up data represent those throughout the therapy period.

Ventilation Parameters under Adaptive Servo Ventilation
Comparative analysis was made between (1) patients with different ejection fractions (LVEF $<40 \%$, LVEF $40-49 \%$, LVEF $\geq 50 \%$ ) in analogy to HFrEF, HfmrEF, and HFpEF. (2) CSA and normal BNP/NT-pro-BNP with CSA-CSR and elevated BNP/NT-proBNP. (3) CSA-CSR with and without OSA. (4) CSA-CSR \pm OSA with $\mathrm{EF}<40 \%$, EF $40-49 \%$ and $\mathrm{EF} \geq 49 \%$.

\section{Polysomnography}

Attended standardized polysomnography was performed with Alice $3.5^{\circledR}$ and Alice $6.0^{\circledR}$ systems (Respironics ${ }^{\circledR}$ ) $[16,18,28]$. Sleep stages and arousals were analyzed according to criteria described elsewhere $[16,18,28]$, respectively, for patients who had participated in the SERVE-HF-study to those of the SERVE-HF study [24].

\section{Statistical Analysis}

The results were statistically analyzed, SPSS, version 16.0 (SPSS, Inc., Chicago, IL, USA). The data are presented as means with SD. A 2 -sided $t$ test with a $p$ value of $<0.05$ was considered to indicate statistical significance.

\section{Results}

From April 2004 to December 2009, 70 patients with a central sleep apnoea (CPAP resistant/emergent CSA or CSA-CSR \pm OSA) had follow-up studies and were included into the analysis; 7 of them had participated in the SERVE-HF-study. Mean follow-up time was $8.2 \pm 3.0$ weeks. Twenty-five patients had CPAP resistant/emergent CSA with normal BNP/NT-pro-BNP, of whom 10 patients had been treated with CPAP over 16 weeks (median); 45 patients had CSA-CSR with an elevated BNP/NT-pro-BNP level, $n=13$ with pure CSACSR (CSA-CSR-OSA) and $n=32$ with CSA-CSR + OSA. Neither the $\mathrm{pCO}_{2}$ before starting ASV $(36.1 \pm 2.8$ vs. $35.9 \pm 5.4$ vs. $36.0 \pm 3.3 \mathrm{~mm} \mathrm{Hg})$ nor the BMI (30.7 \pm 4.4 vs. $29.4 \pm 4.9$ vs. $31.1 \pm 6.1 \mathrm{~kg} / \mathrm{m}^{2}$ were different between these 3 groups. BMI and $\mathrm{pCO}_{2}$ values before starting ASV were also comparable between patients with reduced and preserved left ventricular ejection fraction.

\section{Comparison of ASV in Patients with Different}

Ejections Fractions Regardless of CSA-Type and BNP/NT-Pro-BNP

Sixteen patients had an LVEF $<40 \%, 8$ patients an LVEF $40-49 \%$ and 36 patients an LVEF $\geq 49 \%$. There were no significant differences in minute ventilation, RR, and tidal volume between the first night (i.e., baseline) on ASV and the follow-up period or between the subgroups $($ Fig. $1 \mathrm{a}-\mathrm{c})$. Also, therapeutic pressures were not different (Table 1). 
Fig. 1. a Minute ventilation, (b) RR, and (c) tidal volume during the first night on ASV and during follow-up with ASV in all ASV patients separated by different ejection fractions. ns, not significant; RR, respiratory rate; $\mathrm{ASV}$, adaptive servo-ventilation.

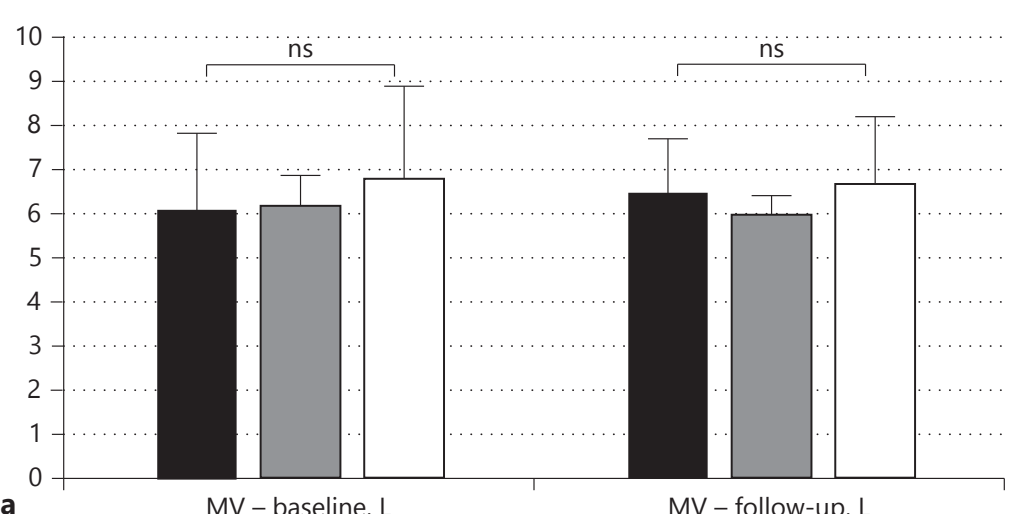

$\mathrm{MV}$ - baseline, $\mathrm{L}$

MV - follow-up, L
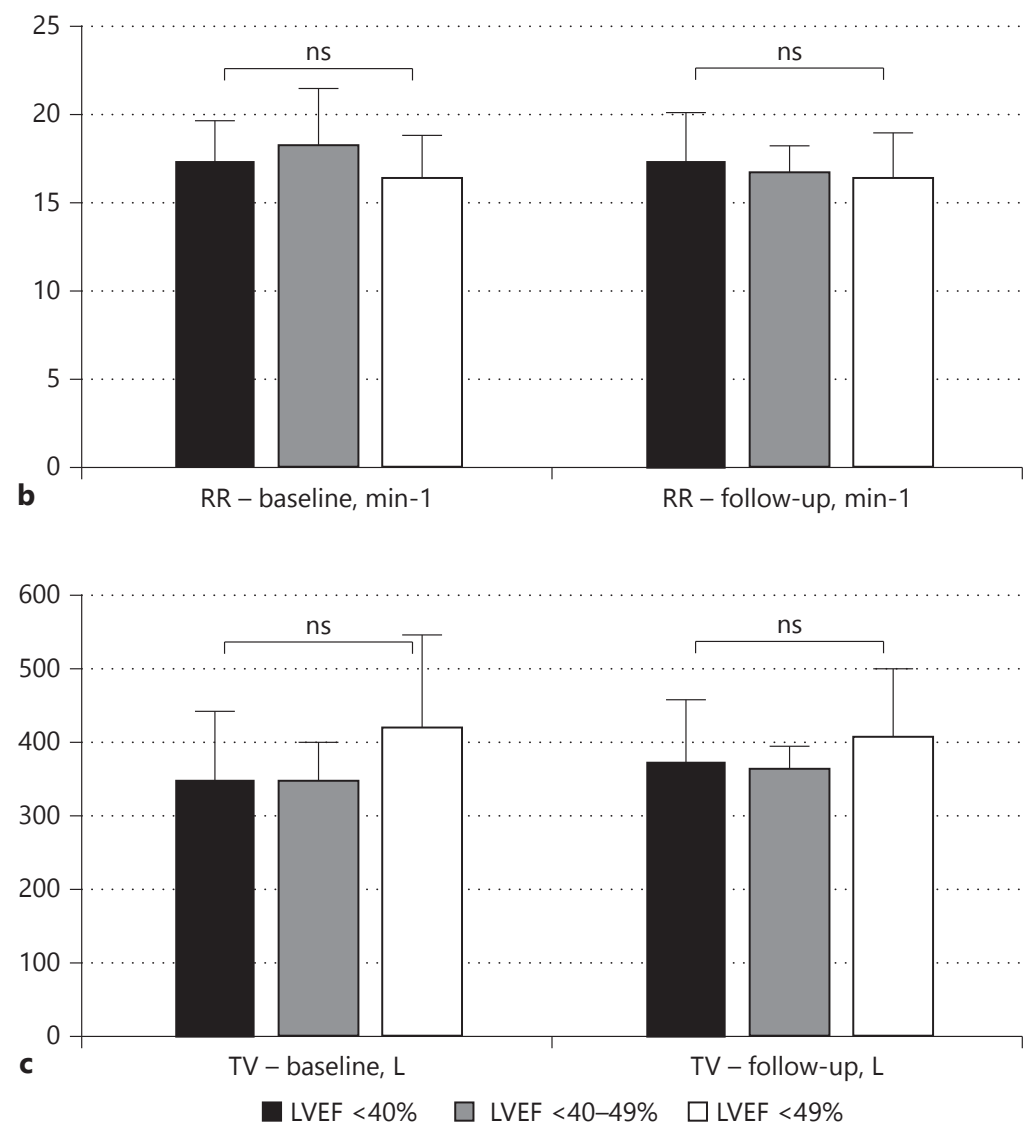

Comparison of CPAP Resistant/Emergent CSA with Normal BNP and CSA-CSR \pm OSA with Elevated $B N P / N T$-Pro-BNP

Patients with elevated BNP/NT-pro-BNP and CSA-CSR \pm OSA had significantly higher RRs $(p<0.01)$ and lower tidal volumes $(p<0.01)$ in the first night on ASV as well as over the follow-up time, whereas MV,
EEP, Pmean, and Ppeak were not different (Table 2; Fig. 2a-c).

Ten patients, who had been referred to the sleep lab because of CPAP-resistant CSA (median treatment time 16 weeks), were not different in terms of minute ventilation, $\mathrm{RR}$, and therapeutic pressure compared to the other patients in the group ofCSA with normal BNP/NT-pro-BNP. 
Table 1. EEP, Ppeak, and Pmedian at baseline (first night on ASV) and during follow-up period with ASV in patients with different left ventricular ejection fractions

\begin{tabular}{lllllll}
\hline & $\begin{array}{l}\text { EEP-baseline } \\
(\mathrm{hPa})\end{array}$ & $\begin{array}{l}\text { EEP-follow-up } \\
(\mathrm{hPa})\end{array}$ & $\begin{array}{l}\text { Ppeak-median - } \\
\text { baseline }(\mathrm{hPa})\end{array}$ & $\begin{array}{l}\text { Ppeak-median - } \\
\text { follow-up (hPa) }\end{array}$ & $\begin{array}{l}\text { Pmedian - baseline } \\
(\mathrm{hPa})\end{array}$ & $\begin{array}{l}\text { Pmedian - } \\
\text { follow-up (hPa) }\end{array}$ \\
\hline $\mathrm{EF}<40 \%$ & $5.3 \pm 0.6$ & $5.5 \pm 0.7$ & $9.5 \pm 1.2$ & $9.8 \pm 1.2$ & $6.9 \pm 0.6$ & $7.2 \pm 0.9$ \\
$\mathrm{EF} 40-49 \%$ & $5.5 \pm 1.7$ & $5.5 \pm 1.7$ & $10.0 \pm 1.8$ & $9.8 \pm 1.6$ & $7.6 \pm 1.9$ & $7.3 \pm 1.6$ \\
$\mathrm{EF}>49 \%$ & $5.6 \pm 1.0$ & $5.6 \pm 1.0$ & $9.6 \pm 1.3$ & $9.7 \pm 1.3$ & $7.2 \pm 1.0$ & $7.3 \pm 1.2$ \\
\hline
\end{tabular}

Table 2. EEP, Ppeak, and Pmedian at baseline (first night on ASV) and during follow-up period with ASV in patients with CSA-CSR \pm OSA and elevated BNP/NT-pro-BNP compared to patients with CPAP resistant/emergent CSA and normal BNP/NT-pro-BNP

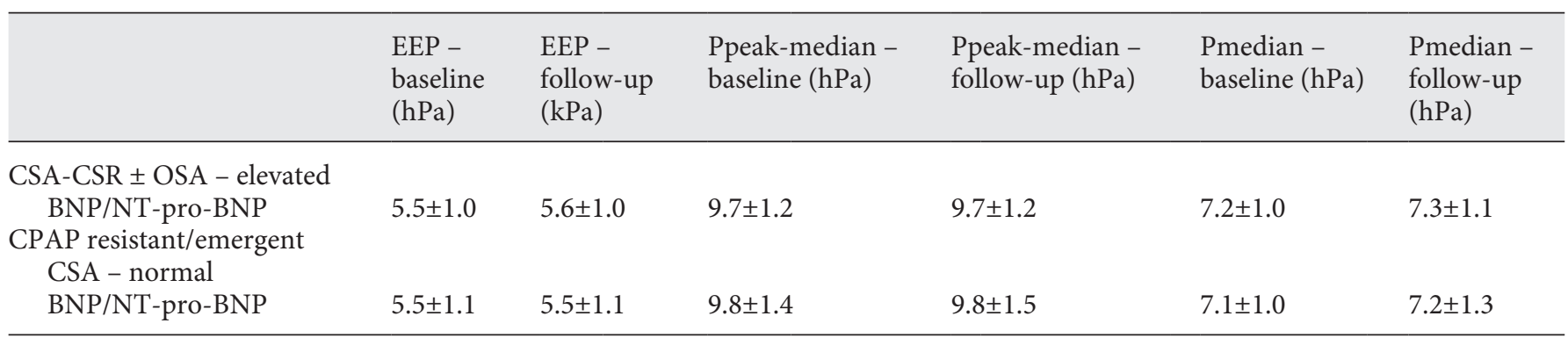

\section{Comparison of Heart Failure Patients with}

CSA-CSR-OSA and CSA-CSR + OSA

Patients with CSA-CSR-OSA $(n=13)$ as well as CSA-CSR + OSA $(n=32)$ had similar RR at baseline $(17.9 \pm 2.7$ vs. $17.1 \pm 2.7 / \mathrm{min})$ and during follow-up $(18.0 \pm 2.1$ vs. $17.1 \pm 2.5 / \mathrm{min}$ ). Also, MV (baseline: 6.3 \pm 1.3 vs. $6.4 \pm 1.7 \mathrm{~L}$; follow-up: $6.5 \pm 0.9$ vs. $6.5 \pm 1.5 \mathrm{~L}$ ), the corresponding tidal volumes (baseline: $350 \pm 55$ vs. $388 \pm 108 \mathrm{~mL}$; follow-up: $363 \pm 35$ vs. $382 \pm 90 \mathrm{~mL}$ ) as well as the therapeutic pressures (EEP - baseline: $5.4 \pm$ 0.8 vs. $5.6 \pm 1.0 \mathrm{hPa}$, follow-up: $5.4 \pm 0.8$ vs. $5.8 \pm 1.0$ $\mathrm{hPa}$; Ppeak - baseline: $9.7 \pm 1.1$ vs. $9.6 \pm 0.8 \mathrm{hPa}$, followup: $9.3 \pm 1.0$ vs. $9.9 \pm 1.3 \mathrm{hPa}$ ) were not significantly different.

\section{Comparison of Patients with Different Ejection \\ Fractions (EF $<40 \%, E F \quad 40-49 \%, E F \geq 49 \%)$ \\ in the Group CSA-CSR \pm OSA and Elevated \\ $B N P / N T$-Pro-BNP}

Sixteen patients had an LVEF $<40 \%$ (HFrEF), 8 patients an LVEF $40-49 \%$ (HFmrEF), and 23 patients an LVEF $>49 \%$ (HFpEF). There were no differences in therapeutic pressures at baseline and during follow-up. Also the minute ventilation, the RRs, and the tidal volumes were not significantly different (Fig. 3a-c).
Ventilation Parameters under Adaptive Servo Ventilation

\section{Discussion}

To our knowledge, this is the first time that data about ventilatory parameters in patients with different types of central sleep apnoea treated with adaptive servoventilation are presented. The results provide insight into breathing patterns, especially minute ventilation and RR, as well as effectively applied therapeutic pressures in these patients. They show that patients with CSA and normal BNP/NT-pro-BNP breathe differently compared to patients with CSA/CSR \pm OSA and elevated BNP/NT-proBNP although both have a normalized AHI using adaptive servoventilation.

\section{CSA-Pattern and Ventilation Parameters}

Breathing patterns in central sleep apnoea can be quite different, varying from short cycle length to typical "crescendo and descrescendo" with long cycles in CSA-CSR [6, 7, 29-31]. Solin et al. [32] showed that hypercapnic ventilatory responses in patients with idiopathic central sleep apnoea were the same in patients with and without diastolic dysfunction. Mansfield et al. [33] reported that a successful heart transplantation led to a switch from CSA-CSR to (I)CSA. These observations implicate that an individual $\mathrm{CO}_{2}$ susceptibility or respiratory ventilatory response to hypocapnia may 
Fig. 2. a Minute ventilation, (b) RR, and (c) tidal volume at first night on ASV and during follow-up with ASV in patients with CSA-CSR \pm OSA and elevated BNP/NTpro-BNP compared to patients with CPAP resistant/emergent CSA and normal BNP/ NT-pro-BNP. ns, not significant; RR, respiratory rate; ASV, adaptive servo-ventilation.

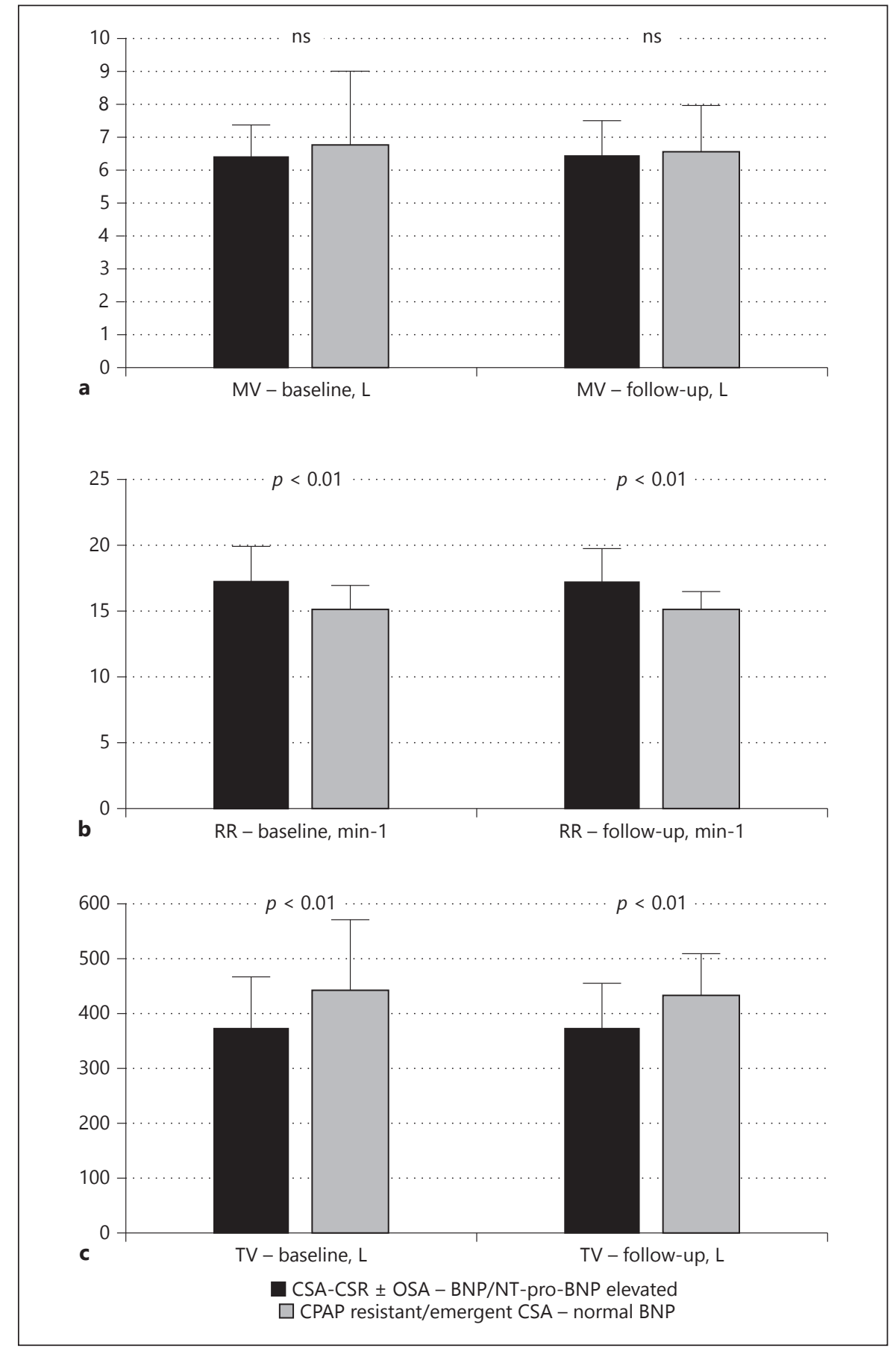

predispose to CSA, with transitions from idiopathic CSA to CSA-CSR in case of heart failure with disturbed autonomic control. Despite these pathophysiological similarities and a similar $\mathrm{pCO}_{2}$ at baseline as well as a normalized RDI in all patients treated with ASV, patients with CSA-CSR and elevated BNP/NT-pro-BNP behave significantly different in terms of RRs under
ASV compared to patients with CPAP-resistant/emergent CSA and normal BNP, showing higher RRs and lower tidal volumes by similar minute ventilation. This implicates that the patients with elevated BNP/NT-proBNP levels and CSA-CSR breathe a lower tidal volume and are supposed to have more dead space ventilation than patients with CSA and normal BNP. Interestingly 
Fig. 3. a Minute ventilation, (b) RRs, and (c) tidal volume at first night on ASV and during follow-up with ASV in CSA-CSR \pm OSA patients with LVEF $<40 \%$, LVEF $40-$ $49 \%$ and LVEF $>49 \%$. ns, not significant; RRs, respiratory rates; ASV, adaptive servo-ventilation.
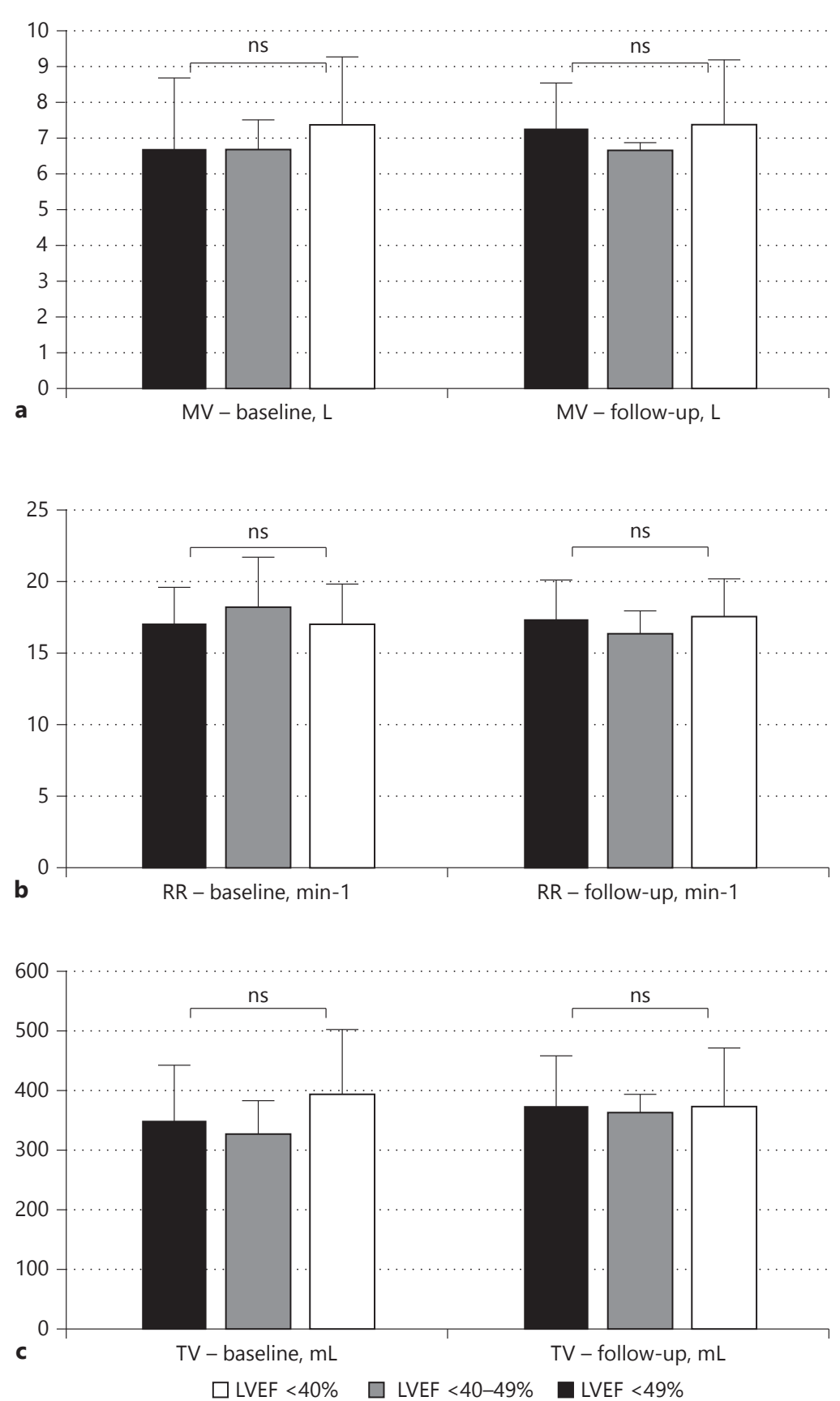

the ventilatory pattern was not significantly different between the first night of ASV and the follow-up period.

The ventilatory parameters of patients with CSACSR + OSA under ASV were not different from those with CSA-CSR-OSA. Therefore, concomitant obstructive sleep apnoea did not influence the breathing pattern. The few patients who had participated in the SERVE-HF study showed the same RRs and tidal volumes as the other patients with CSA-CSR. Nevertheless, it cannot be denied that a CPAP trial might have improved or even normalized the breathing pattern as well as the left ventricular function in some of them because of an additional, even dominant obstructive sleep apnoea, a phenomenon 
described by Tkacova et al. [29] and Ryan and Bradley [34].

Naughton et al. [35] showed that CPAP with a mean pressure of $10.2 \mathrm{~cm} \mathrm{H}_{2} \mathrm{O}$ significantly reduced mean minute ventilation in CSA-CSR from $8.1 \pm 1.0$ to $5.2 \pm 0.5 \mathrm{~L} / \mathrm{min}(p<0.01)$, with an increase of mean Ptc$\mathrm{CO}_{2}$ from $34.6 \pm 1.4$ to $40.8 \pm 1.1 \mathrm{~mm} \mathrm{Hg}(p<0.001)$, although not fully normalizing AHI. Such an increase of $\mathrm{pCO}_{2}$ was not seen in our patients who had follow-up $\mathrm{pCO}_{2}$-testing. The unusually high mean pressure used by Naughton et al. [35], without application of an inspiratory pressure support, has to be discussed as a reason for the lower minute ventilation and higher $\mathrm{pCO}_{2}$ compared to the patients with ASV.

Tkacova and Bradley [36] highlighted that in some patients with heart failure, OSA and CSA are part of a spectrum of periodic breathing that can shift over time in association with alterations in $\mathrm{pCO}_{2}$, cycle length, and probably cardiac function. As many of the patients in the group with CPAP resistant/emergent CSA had cardiac disease [16], they have to be regarded as patients who might shift to CSA-CSR in case of cardiac deterioration with a switch to lower tidal volumes and higher RRs. As ASV normalizes AHI in patients with normal and elevated BNP/NT-pro-BNP, deterioration in cardiac function with transition from CSA to CSACSR might be missed only if the AHI or RDI is looked at. A shift in ventilatory pattern to higher RR and lower minute ventilation should create awareness of such a development.

\section{Ejection Fraction and Ventilation Parameters}

The RR and minute ventilation were not significantly different between patients with normal and reduced ejection fractions (LVEF <40\%, LVEF $40-49 \%$ and LVEF $>49 \%$ ), neither among all patients, nor especially among the group of heart failure patients with CSA-CSR \pm OSA. Former studies [37-41] have shown, that heart failure patients with CSA-CSR do not necessarily have different ejection fractions compared to patients without CSA-CSR. Diastolic dysfunction and restrictive filling pattern of the left ventricle are regarded to be of prognostic relevance and discussed as a more important factor than a reduction of LVEF in promoting the development to CSA-CSR $[42,43]$. As severe central sleep apnoea with an oscillatory breathing pattern is thought to indicate a deterioration of autonomic cardiac control and to represent a marker of abnormal autonomic balance and reflex function $[41,44]$, it implicates that the neuro- humoral activation, but not the LVEF itself, is the causal factor for the development of CSA-CSR and the more restrictive breathing pattern with lower tidal volumes and higher RRs, resulting in more dead space ventilation.

\section{Therapeutic Pressures}

Median as well as maximum inspiratory pressures did not differ neither between the groups of patients with CSA and CSA-CSR nor between the first night of ASV-therapy and the follow-up period. An additional OSA did not result in a higher pressure requirement in CSA-CSR patients. The pressures applied did even not differ from those reported from the SERVE-HF trial with a mean IPAP of 10 mbar and EPAP of 6 mbar [24].

Excessive ventilation or pressures were discussed as a possible explanation for the increase of cardiovascular events in the SERVE-HF study [27]. The data seen in our patients, including the SERVE-HF patients, do not necessarily support this. In patients with CSA-CSR \pm OSA, the median and end-expiratory pressures were rather low and comparable to those applied in patients with CSA and normal BNP. As the data of the devices as well as the polysomnographies in the followup studies showed a normal AHI, an unrecognized persistence especially of obstructive events cannot be supported.

\section{Limitations}

The study is limited by its retrospective character. Not all patients with normal BNP and CPAP resistant/emergent CSA had a longer period of CPAP-therapy before they were switched to ASV. However, 10 patients got CPAP therapy for more than 2 months without normalizing CSA. In case of the other patients, it cannot be excluded that the CSA might have disappeared after a longer time of CPAP use. However, as they presented with a similar low $\mathrm{pCO}_{2}$ at baseline compared to the patients with a longer treatment period with CPAP, both together were regarded as an acceptable group of patients to be compared with CSA-CSR patients.

The study gives information only about the ASVdevice of Resmed ${ }^{\circledR}$. Furthermore, there are no data about the individual ventilation parameters before the initiation of ASV. So, it is not known if ASV had a relevant positive or negative influence on preexisting dead space ventilation, breathing frequency, and minute ventilation in the different subgroups. As the patients with CSA and CSA-CSR presented with a same 
$\mathrm{pCO}_{2}$ at daytime, it would have been expected that both groups exhibit the same ventilatory pattern under ASV. As they did not, it has to be reflected, if they breathe differently only at night or also during the daytime.

A comparison of the device data with parameters of cardiopulmonary exercise testing (CPX), especially the $\mathrm{VE} / \mathrm{VCO}_{2}$-slope, which indicates ventilatory efficacy, correlates with dead space ventilation and is supposed to be an prognostic indicator [42], could not be done and neither has been looked at in former ASV-studies. However, heart failure patients with CSA-CSR, who were shown to have a higher $\mathrm{VE} / \mathrm{VCO}_{2}$-slope than heart failure patients with OSAS, did not experience a decrease of the $\mathrm{VE} / \mathrm{VCO}_{2}$-slope under ASV therapy [17, $21,45,46]$. This indicates a persistence of increased dead space ventilation. Further studies in ASV-therapy of patients with CSA/CSA-CSR should address these open questions.

\section{Conclusion}

Patients with CSA-CSR \pm OSA and CPAP resistant/ emergent CSA with normal BNP show similar $\mathrm{pCO}_{2}$ levels at baseline and need similar pressures for normalization of RDI. Despite this, compared to patients with CPAP resistant/emergent CSA and normal BNP/NTpro-BNP, patients with elevated BNP/NT-pro-BNP and CSA-CSR - regardless of concomitant OSA - have higher RRs and lower tidal volumes, but similar minute ventilation under ASV. This indicates higher dead space ventilation in these patients.
A classification based on different ejection fractions, regardless of BNP/NT-pro-BNP levels and the CSA-pattern, does not show any difference in ventilatory parameters. Also in the group with CSA-CSR \pm OSA the minute ventilation, $R R s$ and tidal volumes were not different between patients with HfrEF, HfmrEF, and HFpEF. Therefore, the disturbance of autonomic control in heart failure, but not the ejection fraction itself, seems to influence the ventilatory parameters under ASV and induce higher dead space ventilation compared to other forms of CSA with normal BNP. A shift from CSA to CSA-CSR in case of cardiac deterioration with a switch to more dead space ventilation can be overlooked by only assessing the AHI because ASV may maintain a normal AHI in both situations.

\section{Acknowledgments}

The authors thank the team of the Sleep laboratory of the Hemer Lung Clinic for their technical assistance.

\section{Statement of Ethics}

All procedures performed were in accordance with the ethical standards of the institutional and/or national research committee and with the 1964 Helsinki declaration and its later amendments or comparable ethical standards. Informed consent was obtained from all individual participants included in the study.

\section{Financial Disclosure and Conflicts of Interest}

No funding was received for this research. The authors declare that they have no conflicts of interest to disclose.

\section{References}

1 Solin P, Roebuck T, Johns DP, Walters EH, Naughton MT: Peripheral and central ventilatory responses in central sleep apnoea with and with congestive heart failure. Am J Respir Crit Care Med 2000;162:21942200.

2 Naughton MT: Pathophysiology and treatment of Cheyne-stokes respiration. Thorax 1998;53:514-518.

3 Xie A, Skatrud JB, Puleo DS, Rahko PS, Dempsey JA: Apnea-hypopnea threshold for $\mathrm{CO} 2$ in patients with congestive heart failure. Am J Respir Crit Care Med 2002;165:12451250.

4 Bradley TD, John S, Floras JS: Sleep apnea and heart failure: part II: central sleep apnea. Circulation 2003;107:1822-1826.
5 Xie A, Skatrud JB, Puleo DS, Dempsey JA: Influence of arterial $\mathrm{O} 2$ on the susceptibility to posthyperventilation apnea during sleep. J Appl Physiol 2006;100:171-177.

6 Xie A, Wong B, Phillipson EA, Slutsky AS, Bradley TD: Interaction of hyperventilation and arousal in the pathogenesis of idiopathic central sleep apnea. Am J Respir Crit Care Med 1994;150:489-495.

7 Hall MJ, Xie A, Rutherford R, Ando S, Floras JS, Bradley TD: Cycle length of periodic breathing in patients with and without heart failure. Am J Respir Crit Care Med 1996;154: 376-381.

8 Sullivan CE, Berthon-Jones M, Issa FG, Eves L: Reversal of obstructive sleep apnea by continuous positive airway pressure ap- plied through the nose. Lancet 1981;1:862865 .

9 Issa FG, Sullivan CE: Reversal of central sleep apnea using nasal CPAP. Chest 1986;90:165171.

10 Solin P, Roebuck T, Swieca J, Walters EH, Naughton MT: Effects of cardiac dysfunction on non-hypercapnic central sleep apnea. Chest 1998;113:104-110.

11 Verbraecken J, Willemen M, Wittesaele W, van de Heyning $\mathrm{P}$, de Backer W: Short-term $\mathrm{CPAP}$ does not influence the increased $\mathrm{CO}_{2}$ drive in idiopathic central sleep apnea. Monaldi Arch Chest Dis 2002;57:10-18.

12 White DP: Pathogenesis of obstructive and central sleep apnea. Am J Respir Crit Care Med 2005;172:1363-1370.
Ventilation Parameters under Adaptive Servo Ventilation 
13 Morgenthaler TI, Gay PC, Gordon N, Brown LK: Adaptive servoventilation versus noninvasive positive pressure ventilation for central, mixed, and complex sleep apnea syndromes. Sleep 2007;30:468-475.

14 Pusalavidyasagar SS, Olson EJ, Gay PC, Morgenthaler TI: Treatment of complex sleep apnea syndrome: a retrospective comparative review. Sleep Med 2006;7:474-479.

15 Allam JS, Olson EJ, Gay PC, Morgenthaler TI: Efficacy of adaptive servoventilation in treatment of complex and central sleep apnea syndromes. Chest 2007;132:1839-1846.

16 Westhoff M, Arzt M, Litterst P: Influence of adaptive servoventilation on B-type natriuretic petide in patients with Cheyne-Stokes respiration and mild to moderate systolic and diastolic heart failure. Pneumologie 2010;64: 467-473.

17 Bitter T, Westerheide N, Faber L, Hering D, Prinz C, Langer C, Horstkotte D, Oldenburg $\mathrm{O}$ : Adaptive servoventilation in diastolic heart failure and Cheyne-Stokes respiration. Eur Respir J 2010,36:385-392.

18 Westhoff M, Arzt M, Litterst P: Prevalence and treatment of central sleep apnoea emerging after initiation of continuous positive airway pressure in patients with obstructive sleep apnoea without evidence of heart failure. Sleep Breath 2012;16:71-78.

19 Teschler H, Döhring J, Wang YM, BerthonJones M: Adaptive pressure support servoventilation: a novel treatment for CheyneStokes respiration in heart failure. Am J Respir Crit Care Med 2001;164:614-619.

20 Pepperell JC, Maskell NA, Jones DR, Langford-Wiley BA, Crosthwaite N, Stradling JR, Davies RJ: A randomized controlled trial of adaptive ventilation for Cheyne-Stokes breathing in heart failure. Am J Respir Crit Care Med 2003;168:1109-1114.

21 Oldenburg O, Schmidt A, Lamp B, Bitter T, Muntean BG, Langer C, Horstkotte D: Adaptive servoventilation improves cardiac function in patients with chronic heart failure and Cheyne-Stokes respiration. Eur J Heart Fail 2008; $10: 581-586$.

22 Oldenburg O, Bitter T, Lehmann R, Korte S, Dimitriadis Z, Faber L, Schmidt A, Westerheide N, Horstkotte D: Adaptive servoventilation improves cardiac function and respiratory stability. Clin Res Cardiol 2011;100:107115.

23 Birner C, Series F, Lewis K, Benjamin A, Wunderlich S, Escourrou P, Zeman F, Luigart R, Pfeifer M, Arzt M: Effects of auto-servo ventilation on patients with sleep-disordered breathing, stable systolic heart failure and concomitant diastolic dysfunction: subanalysis of a randomized controlled trial. Respiration 2014;87:54-62.

24 Cowie MR, Woehrle H, Wegscheider K, Angermann C, d'Ortho MP, Erdmann E, Levy P, Simonds AK, Somers VK, Zannad F, Teschler $\mathrm{H}$ : Adaptive servo-ventilation for central sleep apnea in systolic heart failure. N Engl J Med 2015;373:1095-1105.

25 Yamauchi M, Combs D, Parthasarathy S: Adaptive servo-ventilation for central sleep apnea in heart failure. N Engl J Med 2016;374: 689.

26 Mehra R, Gottlieb DJ: A paradigm shift in the treatment of central sleep apnea in heart failure. Chest 2015;148:848-851.

27 Javaheri S, Brown LK, Randerath W, Khayat R: SERVE-HF: more questions than answers. Chest 2016;149:900-904.

28 Westhoff M, Litterst P: Obstructive sleep apnoea and non-restorative sleep induced by the interface. Sleep Breath 2015;19:1317-1325.

29 Tkacova R, Rankin F, Fitzgerald FS, Floras JS, Bradley TD: Effects of continuous positive airway pressure on obstructive sleep apnea and left ventricular afterload in patients with heart failure. Circulation 1998;98:2269-2275.

30 Bradley TD, McNicholas WT, Rutherford R, Popkin J, Zamel N, Phillipson EA: Clinical and physiologic heterogeneity of the central sleep apnea syndrome. Am Rev Respir Dis 1986;134:217-221.

31 Xie A, Rutherford R, Rankin F, Wong B, Bradley TD: Hypocapnia and increased ventilatory responsiveness in patients with idiopathic central sleep apnea. Am J Respir Crit Care Med 1995;152:1950-1955.

32 Solin P, Jackson DM, Roebuck T, Naughton MT: Cardiac diastolic function and hypercapnic ventilatory responses in central sleep apnoea. Eur Respir J 2000;20:717-723.

33 Mansfield DR, Solin P, Roebuck T, Bergin P, Kaye DM, Naughton MT: The effect of successful heart transplant treatment of heart failure on central sleep apnea. Chest 2003;124: 1675-1681.

34 Ryan CM, Bradley TD: Periodicity of obstructive sleep apnea in patients with and without heart failure. Chest 2005; 127:536-542.

35 Naughton MT, Benard DC, Rutherford R, Bradley TD: Effect of continuous positive airway pressure on central sleep apnea and nocturnal PCO2 in heart failure. Am J Respir Crit Care Med 1994;150:1598-1604.

36 Tkacova R, Bradley TD: Night-to-night alterations in sleep apnea type in patients with heart failure. J Sleep Res 2006;15:321328.

37 Hanly PJ, Zuberi-Khokhar NS: Increased mortality associated with Cheyne-Stokes respiration in patients with congestive heart failure. Am J Respir Crit Care Med 1996;153: 272-276.

38 Krachman SL, D’Alonzo GE, Berger TJ, Eisen $\mathrm{HJ}$ : Comparison of oxygen therapy with nasal continuous positive airway pressure on Cheyne-Stokes respiration during sleep in congestive heart failure. Chest 1999;116: 1550-1557.

39 Sin DD, Logan AG, Fitzgerald FS, Liu PP, Bradley TD: Effects of continuous positive airway pressure on cardiovascular outcomes in heart failure patients with and without Cheyne-Stokes respiration. Circulation 2000; 102:61-66.

40 Ponikowski P, Anker SD, Chua TP, Francis D, Banasiak W, Poole-Wilson PA, Coats AJ, Piepoli M: Oscillatory breathing patterns during wakefulness in patients with chronic heart failure: clinical implications and role of augmented peripheral chemosensitivity. Circulation 1999;100:2418-2424.

41 Lanfranchi PA, Somers VK, Braghiroli A, Corra U, Eleuteri E, Giannuzzi P: Central sleep apnea in left ventricular dysfunction: prevalence and implications for arrhythmic risk. Circulation 2003;107:727-732.

42 Yu HC, Sanderson JE: Different prognostic significance of right and left ventricular diastolic dysfunction in heart failure. Clin Cardiol 1999;22:504-512.

43 Enriquez-Sarano M, Rossi A, Seward JB, Bailey KR, Tajik AJ: Determinants of pulmonary hypertension in left ventricular dysfunction. J Am Coll Cardiol 1997;29:153-159.

44 Ponikowski P, Francis DP, Piepoli MF, Davies LC, Chua TP, Davos CH, Florea V, Banasiak W, Poole-Wilson PA, Coats AJ, Anker SD: Enhanced ventilatory response to exercise in patients with chronic heart failure and preserved exercise tolerance: marker of abnormal cardiorespiratory reflex control and predictor of poor prognosis. Circulation 2001;103:967972

45 Wedewardt J, Bitter T, Prinz C, Faber L, Horstkotte D, Oldenburg O: Cheyne-Stokes respiration in heart failure: cycle length is dependent on left ventricular ejection fraction. Sleep Med 2010;11:137-142.

46 Bitter T, Westerheide N, Hossain MS, Lehmann R, Prinz C, Kleemeyer A, Horstkotte D, Oldenburg O: Complex sleep apnoea in congestive heart failure. Thorax 2011;66:402-407. 